\title{
FORMAS DE AISLAMIENTO FÍSICO Y SIMBÓLICO: LA LEPRA, SUS ESPACIOS DE RECLUSIÓN Y EL DISCURSO MÉDICO-LEGAL EN ARGENTINA
}

\author{
Marisa Miranda y Gustavo Vallejo
}

IIB-INTECH/CONICET-UNSAM

\begin{abstract}
RESUMEN
Durante la primera mitad del siglo XX la presencia de la lepra en sociedades modernas suscitó variadas reacciones. Aun sin que desaparecieran ancestrales prejuicios, el discurso médico-legal abordó un problema que excedía el marco estrictamente sanitario. El trabajo analiza el modo en que, desde una perspectiva científica, fueron gestadas en Argentina respuestas que creyeron hallar en el aislamiento físico y simbólico del leproso una forma proteger la población y el futuro de la raza. En ese contexto, la eugenesia legitimó fuertes restricciones de derechos a enfermos sobre los que siguió pesando aquel estigma ancestral.
\end{abstract}

PALABRAS CLAVE: Lepra. Eugenesia. Espacios de aislamiento.

WAYS OF PHYSICAL AND SYMBOLIC ISOLATION: LEPROSY, ITS ISOLATION SPACES AND THE MEDICAL-LEGAL DISCOURSE IN ARGENTINA

\begin{abstract}
During the first half of the twentieth century, the presence of leprosy in modern societies provoked various reactions. As ancient prejudices had not disappeared yet, the medical-legal discourse dealt with a problem that exceeded the strictly sanitary framework. From a scientific perspective, this paper analyzes the way in which answers find that seemed the population and the future of the race in the physical and symbolic isolation of the leper, were developed in Argentina. In that context, the eugenics legitimated strong restrictions of rights to sick persons on whom this ancestral stigma continued to carry much weight.
\end{abstract}

KEY WORDS: Leprosy. Eugenics. Isolation spaces.

\section{LEPRA Y AISLAMIENTO}

Desde que en el siglo XIX las nuevas naciones latinoamericanas buscaron organizarse a partir de un sistema de derechos y garantías regido por el reno- 
vado significado que la Revolución Francesa le dio a la noción de ciudadanía, el aislamiento por una explícita o implícita decisión del poder público expresó sus límites, fijó la frontera que a menudo por una «razón de Estado» pasó a distinguir la inclusión y la exclusión dentro de un sistema de derechos.

El aislamiento en el mundo moderno particulariza un problema que en materia de salud tiene una larga data y ha sido objeto de diversas interpretaciones. En efecto, la restringida forma en que sociedades finiseculares, incluidas las latinoamericanas, abrazaron la idea de ciudadanía, sirvió también para exaltar un sistema de luces y sombras, donde lo «normal y lo patológico» interactuaron permanentemente y favorecieron la prolongación de formas seculares de aislamiento: por un lado el aislamiento físico, que procura separar al enfermo del resto de la sociedad sana con dos finalidades básicas, la de proteger al universo de la «normalidad», esto es a los sanos, y la de asistir y/o curar a lo «patológico»; y por otro, el aislamiento simbólico, más próximo a la interdictio romana, planteado como un distanciamiento del sistema de derechos, puesto de manifiesto como una restricción de la capacidad para adquirirlos o ejercerlos, que no implica necesariamente una separación física del otro.

Esa tensión entre derechos y formas de restricción a su ejercicio, signó la emergencia de la eugenesia, ciencia con la que Galton y sus epígonos llegaron a imaginar un modo racional de acoplar ambos tipos de aislamiento, el físico y el simbólico, a través de la invocación al futuro de la raza como estrategia biopolítica basada en la partición binaria entre lo «normal» y lo «patológico».

La temprana recepción de la eugenesia en Argentina, permitió movilizar un discurso médico-legal tendente a combatir diversas enfermedades y aislar - en ambos sentidos - a quienes las padecían; en parte, por asistencialismo y caridad, pero también, por constituir «focos disgénicos» que amenazaban con alterar las pretendidas cualidades «raciales» de la población. Dentro de este marco, cabe situar las representaciones y las respuestas legales y materiales generadas durante la primera mitad del siglo XX para afirmar el aislamiento de los leprosos, teniendo en cuenta la importancia de estas acciones para afirmar un paradigma eugénico.

Sabido es que la lepra ha sido históricamente la enfermedad más tematizada por metáforas que instaban a enfrentarla a través de la segregación de sus portadores con el objetivo primordial de impedir el contagio ${ }^{1}$. No obstante, la

1 La segregación también tenía un carácter punitivo: en la Edad Media se creía que por la corrupción del cuerpo emergía la enfermedad del alma, producto de herejías, lujurias y el peor de los pecados, el sexual. Le Goff, J. y TRUONG, N. (2005), Una historia del cuerpo en la Edad Media, Buenos Aires, Paidós, pp. 91-92. 
ubicación de los problemas que acarreaba dentro del Estado moderno, la dotó de nuevas significaciones que quedaron inmersas en el concepto finisecular de «defensa social». En efecto, y a diferencia de la larga duración que la historia de esa enfermedad presenta en Europa, la lepra en Argentina tiene una escasa entidad antes de la segunda mitad del siglo XVIII ${ }^{2}$, y el tema se pone verdaderamente en discurso desde fines del siglo XIX ${ }^{3}$, cuando irrumpe la prolífica labor de médicos y legistas en torno al manejo biopolítico de la enfermedad y del enfermo. De esta labor, realizada a veces en sintonía con los Congresos Internacionales de la materia - el Primer Congreso Internacional de la Lepra se reunió en Berlín en 1897-y, a veces, generando propia doctrina, dan cuenta los numerosos proyectos legislativos que se suceden sin descanso desde el año 1908 hasta la sanción, en 1926, de la Ley 11.359. El primero de esos proyectos surgió de las conclusiones a las que arribó la Conferencia Nacional sobre la Lepra, celebrada a instancias del gobierno nacional en $1906^{4}$. Finalmente, en 1926, tuvo encarnación normativa la primer Ley nacional de Profilaxis de la Lepra que, basada en un proyecto del doctor Maximiliano Aberastury, reguló la actitud estatal para con el hanseniano ${ }^{5}$, sin mayores modificaciones, hasta su derogación definitiva en 1983, evento que constituyó uno de los últimos actos del gobierno dictatorial que asumiera en 1976. En el aspecto que nos ocupa, esta Ley condensó sendos aislamientos: el distanciamiento físico del enfermo de sus congéneres - ya sea en su domicilio o en asilos o colonias - y el aislamiento simbólico o formal a través de la prohibición de contraer nupcias, restricción que constituye el primer impedimento matrimonial de orden eugenésico legislado en Argentina. La acción asistencial de la medicina se articuló entonces con el derecho, y el tratamiento efectivo para la cura del enfermo fue sólo parte de un problema mayor que se desplazó hacia una directa reducción de derechos civiles.

Dentro de esta consideración de la lepra como un problema que llegó a vincular la asistencia con la eugenesia, se iluminan a su vez los dos tiempos

2 Quiroga, M. (1964), Historia de la Lepra en Argentina, Buenos Aires, Academia Nacional de Medicina, p. 25.

3 Para un abordaje reciente de la lepra en Argentina véase: MolinARI, I. (2005), Los 'Desheredados de la vida': el primer sanatorio-colonia para enfermos de lepra, Revista de Historia, (1), 169-184.

4 Conferencia sobre la Lepra (1908), Buenos Aires, Talleres Gráficos de la Penitenciaría Nacional.

5 El nombre hanseniano, que alude a Gerhard A. Hansen, el descubridor del bacilo causal de la lepra, comenzó a utilizarse especialmente desde que la Conferencia Internacional de Lepra de 1948 celebrada en La Habana, promoviera su uso en honor al médico, en lugar del término «leproso» que se refería peyorativamente a los enfermos. 
en los que la enfermedad es pensada. El presente del tratamiento del enfermo a través del aislamiento físico, y el futuro de la mejora de la raza por medio de la restricción de derechos civiles a hansenianos. Integrando esos dos tiempos aparecen espacios para la reclusión como lo fue, hasta 1968, la Colonia de la Isla del Cerrito, en Chaco.

\section{EL ESPACIO DE LA LEPRA: RECLUIR LO «ANORMAL»}

El aislamiento del leproso en Argentina adoptó, en términos físicos, una forma precisa que prevaleció hasta entrada la década de 1960. En ella primó la figura de la colonia extraurbana, enclavada en un sitio que debía emblematizar su inaccesibilidad por la sola invocación del accidente geográfico que lo contendría: una isla.

Desde 1906 aquel espacio de aislamiento fue afirmándose dentro de representaciones que terminaron convirtiéndose casi en un lugar común. Ellas volvían sobre las características básicas que adquirió el sistema Open-Door para atender la locura, el cual tras ser aplicado por primera vez en la reestructuración que Alejandro Korn llevó a cabo en 1897 en el Hospital neuropsiquiátrico de Melchor Romero (La Plata) ${ }^{6}$, se extendió por impulso de Domingo Cabred al Hospicio de Mercedes y los Asilos-Colonia de Luján y Lomas de Zamora y luego a todo el país a través de un plan de vastos alcances. Sus preceptos básicos podían sintetizarse en amplitud de los espacios para favorecer la vida higiénica, tierras para desarrollar la «laborterapia» que, además de hacer sentir al colono apto para el trabajo, aseguraran el medio de subsistencia de la propia colonia, una adecuada distancia de los centros urbanos para que la libertad para moverse en las tierras que trabajaban no supusiera un riesgo por posibles contactos con el universo de la «normalidad», y un hábitat con forma de chalets para asimilar su imagen a un tipo de vivienda individual anhelada. El sistema de casas separadas, también permitía mantener, aun dentro del aislamiento, las diferencias de clases de los enfermos que llegaban a la colonia, para evitar que, en el interior del complejo, existiesen formas organizativas diferenciadas de las de la sociedad burguesa extendida extramuros?

6 Vallejo, G. (2007), Escenarios de la cultura científica argentina. Ciudad y Universidad (1882-1955), Madrid, CSIC.

7 La Colonia Open-Door fue promovida por una Ley sancionada en 1895 con base en preceptos enunciados por Cabred, luego de que éste viajara a Europa enviado por el gobierno argentino para informarse de los nuevos sistemas asilares, y se interiorizara del modelo esco- 
Las características físicas de los espacios para el aislamiento de leprosos fueron precisadas ya en la Conferencia Nacional de la Lepra de 1906. Allí Antonio Pont - delegado por la Provincia de Corrientes - consideró la idea de asilo-colonia particularmente adecuada a «la forma crónica de la enfermedad, la tendencia a la vida nómada y a respirar en libertad, del leproso», para quien era necesario «el aislamiento en un establecimiento grande, con campo, mucho campo, vegetación, aire que respirar, entretenimiento [y] trabajos compatibles con su estado» ${ }^{8}$. Pont agregaba que la colonia que reuniría todos aquellos atributos debía ser

«mixta, un pequeño pueblo de casas separadas, agrupadas de veinte en veinte o de treinta en treinta, con calles anchas, bien ventiladas, unas; con el confort y comodidades necesarias para los pensionistas ricos a quienes se les deberá permitir la construcción de chalets, donde vivir solos o acompañados de algún miembro de su familia si así lo desea, con servicio que podría reclutar de la misma colonia, retribuyéndolo; con construcciones higiénicas para el pobre; con balneario, pabellón de curaciones; pabellón de aislamiento para los hijos de los leprosos que naciesen en la misma; otro para afecciones intercurrentes y complicaciones, y un pequeño asilo para los mutilados y en estado caquéctico. En una palabra: una gran colonia, en que aparte de la reclusión obligada, los enfermos viviesen la vida común, con todas las condiciones higiénicas y de curación de un sanatorio moderno, resolviendo el problema leproso nacional de un modo científico y económico»»?

Y estas características que claramente situaban al tratamiento de la lepra en directa correspondencia con la locura, para la cual había sido prescripto el sistema Open-Door, eran contrapuestas a otras prefiguraciones. Las colonias representaban la forma más avanzada de ocuparse de la lepra, al ofrecer una opción ampliamente superadora de las tradicionales leproserías, entre otras cosas porque en la colonia el enfermo «trabaja, se siente útil, y además aporta

cés. Se trataba de «un conjunto de disposiciones de orden material y de régimen interno que tienden, todas, a dar al establecimiento el aspecto de un pueblo, a proporcionar a sus moradores la mayor suma de libertad, compatible con su estado de locura, y a hacer del trabajo uno de los elementos más importantes del tratamiento moral». Era un sistema sin «muros de circunvalación que oculten el horizonte, ni nada que despierte la idea del encierro, y así la ilusión de libertad será completa». CABRED; D., Discurso sobre asilos y hospitales regionales en la República Argentina (Ley 4953); cfr. Vezzetti, H. (1985), La locura en Argentina, Buenos Aires, Paidós, p. 79.

8 Pont, A. (1908), Informe presentado a la Conferencia por el Dr. Antonio B. Pont, Conferencia sobre la Lepra, pp. 185-250, p. 225.

9 PONT (1908), p. 225. 
dinero» ${ }^{10}$. Asimismo, dentro de la colonia, el sistema de casas separadas permitía expresar las diferencias de estatus de cada enfermo, algo que también sobrevaloró la Conferencia Nacional de la Lepra al promover una forma de tratamiento desigual para ricos y pobres afectados por ese mal.

«Dado el ambiente social saturado de ideas de altruismo, humanidad y libertad de la Argentina, contrario a las violencias [...] tendremos que decidirnos por aceptar una ley diferencial de aislamiento obligatorio para el pobre, facultativa para el rico, ley cruel tal vez para el desheredado de la fortuna, cuya libertad se atropella, y que recuerda las de castas abolidas por la revolución y las conquistas modernas, únicamente disculpable, dado el fin humanitario que se persigue y la menor resistencia que su ejecución ha de ocasionar» ${ }^{11}$.

Era en definitiva un aislamiento obligatorio diferencial semejante al previsto en la Ley provincial dictada en Corrientes en $1901^{12}$.

Pont también previó la localización de la colonia en una isla que podía situarse en el Atlántico. Baldomero Sommer coincidió en ello y precisó que esa isla debía ser «lo suficientemente amplia para poder destinar una parte a la agricultura y otra parte a la ganadería». Y más que buscarla en el Atlántico, convenía recurrir a la emblemática isla Martín García, en el Río de La Plata. La misma isla que Domingo Sarmiento en 1850 había imaginado como lugar de una gran utopía: la de la Confederación de Estados Sudamericanos que tendrían allí su capital, denominada Argirópolis ${ }^{13}$. La isla Martín García era así objeto de representaciones que se desplazaban de la utopía a la distopía, del centro de confluencia de los intereses regionales al sitio de aislamiento para enfermos incurables, donde lo producido no podría salir de la isla e incluso los propios empleados del establecimiento debían ser leprosos para favorecer la comunión de todos aquellos que formaban parte de ese universo de

10 Sommer, B. (1908), Formas clínicas, Profilaxis y tratamiento de la Lepra, Conferencia sobre la Lepra, pp. 307-313, p. 310.

11 PONT (1908), p. 231. La cursiva es nuestra.

12 En dicha Ley se decía que: «las personas pudientes serán aisladas en su domicilio, siempre que den su palabra de honor de no salir jamás de casa; no dormir con otra persona; que ningún miembro de la familia, ni extraño, usará nunca cosa alguna del servicio o uso del paciente; las personas indigentes serán secuestradas en la leprosería». A su vez, los niños nacidos de padres leprosos indigentes eran aislados en observación en establecimientos especiales «antes de darles otro destino», mientras que los niños autorizados a vivir en sus domicilios, no podían concurrir a la escuela. Cfr. Conferencia sobre la Lepra (1908), pp. 247-252, p. 247.

13 SARmiento, D. (1916) [1850], Argirópolis, Buenos Aires, La Cultura Argentina. 
la otredad que quedaba aislado ${ }^{14}$. Pero es que la propia ubicación de la isla frente a las costas argentinas y uruguayas, que derivó en largas disputas entre ambos países por su posesión, también inducía a pensar en un destino que, en el caso de la utopía sarmientina, debía trascender los intereses nacionales y en el de Sommer implicaba llegar a los límites geográficos llevando a esos confines la esfera de «anormalidad» patológica.

La colonia se conformaría «por un edificio principal destinado a la administración. Salas de enfermos de tamaños variados, con sus departamentos», y además debían existir «casitas, en las cuales puedan vivir familias o varios leprosos juntos. Debe el gobierno establecer carpinterías, panaderías, herrerías, hornos de ladrillos y demás industrias necesarias para la marcha de la colonia $\rangle^{15}$. Desde el temor al contagio se fundamentaba el aislamiento, se establecía una situación de la que igualmente podía sacarse provecho, en tanto los internos lograran conformar una comunidad autosuficiente que relevara al Estado de gastos excesivos en su mantenimiento. Asimismo, y aun sin conocerse a ciencia cierta la etiología de la enfermedad, se tenía la certeza de que el aire puro, el sol y la limpieza corporal eran factores importantes en el tratamiento. Por eso la Colonia, a la que su condición insular proveería de un balneario natural, debía contemplar, además, la existencia de «una casa de baños, bien amplia, para que los colonos puedan bañarse si es posible, diariamente».

La aplicación del modelo de sanatorios-colonia extraurbanos para un universo que trascendía el de alienados hasta alcanzar a otras enfermedades como la lepra, tuvo un particular impulso desde el momento en el que Cabred asumió la presidencia de la Comisión Asesora de Asilos y Hospitales Regionales en cumplimiento de la Ley 4953 de $1906^{16}$.

Dentro de una lógica que aunaba el pensamiento de Pont y Sommer con el de Cabred, surgió - por encargo de un decreto presidencial de Marcelo T. de Alvear - el Proyecto de Maximiliano Aberastury, que prescribió la creación

14 Para evitar el contagio no se deberían «elaborar productos para mandar fuera de la colonia, sino que todo lo que se fabrique sea para ella». SOMMER (1908), p. 310.

15 SOMMER (1908), p. 310.

16 Entre las instituciones que quedaron comprendidas bajo la órbita del organismo dirigido por Cabred se hallaban: el Asilo Colonia Regional Mixto de Retardados en Torres (Prov. de Buenos Aires), el Asilo-Colonia Regional Mixto de Alienados en Oliva (Prov. de Córdoba), Hospital Común Regional de Resistencia (Prov. de Chaco), Hospital Común Regional de Bell-Ville (Prov. de Córdoba), Asilo-Colonia Regional de Niños Abandonados en Olivera, Mercedes (Prov. de Buenos Aires), Hospital Común Regional Andino (Prov. de La Rioja), Hospital Común Regional de Posadas (Prov. de Misiones), Sanatorio Nacional de Tuberculosos Santa María en Cosquín (Prov. de Córdoba). 
de dos colonias para leprosos. Una de ellas en el Litoral, una región que los precursores estudios del Dr. Fariní sobre lepra en Argentina ya habían destacado en 1899 dentro del contexto nacional ${ }^{17}$. La otra colonia vendría a establecer un equilibrio geográfico en un punto del sur equidistante de la metrópolis argentina. Complementaba estas prescripciones la prohibición de situarlas a una distancia no menor de cincuenta kilómetros de pueblo o ciudad más próxima y la obligación de conectarlas con una vía férrea o fluvial que serviría de único vínculo entre la comunidad de enfermos y la esfera de «normalidad». La nueva colonia de leprosos se incorporaría entonces a la larga lista de instituciones comprendidas en la mencionada Comisión Asesora de Asilos y Hospitales Regionales que seguía comandando Cabred.

En el Proyecto de Aberastury, convertido en 1926 en Ley 11.35918, se precisaban las características que tendrían las colonias para leprosos.

«Serán en lo posible como aldeas, con pabellones ordenadamente distribuidos y dotados de obras de salubridad completas. Se elegirá para ellas terrenos arbolados, con bosques naturales o artificiales, en zonas que permitan una fácil comunicación con el resto del país. Les será dada una extensión suficiente de tierra de la mejor calidad posible, con buenas aguas, de modo que sea posible a los colonos hábiles dedicarse a trabajos de jardinería, huerta, plantaciones de árboles, agricultura, y también a explotaciones agrícologanaderas $(\ldots) »^{19}$.

Aberastury también proponía la Isla del Cerrito, en Chaco, frente a las costas de Corrientes, para cumplir la finalidad de su Proyecto y, apelando a metáforas del campo militar, presagiaba que ella quedaría a la «vanguardia de combate contra la marcha invasora de la lepra», por ser "un hallazgo estratégico para la defensa del Litoral y de gran parte del Norte argentino contra el desarrollo considerable que la lepra ha adquirido en esas regiones» ${ }^{20}$.

Igualmente se esbozaron algunas alternativas a las características señaladas y a su localización. Por un lado Pedro Baliña, profesor titular de la cáte-

17 FARINÍ, J. (1899), La lepra. Apuntes sobre su historia, importación, etiología y geografia, estadística hospitalaria y profilaxis, Buenos Aires, Imprenta de Emilio Spinelli. Fariní también participó de la Conferencia sobre la Lepra de 1906, como delegado por la Capital Federal.

18 El texto completo de esta norma se halla publicado en: Anales de Legislación Argentina (1920-1940), Buenos Aires, pp. 202-206; y en el Boletín Oficial de la República Argentina (1926), Buenos Aires, 18 de octubre.

19 Artículo 23 de la Ley 11.359.

20 Intervención del ministro del Interior, cfr. Diario de Sesiones de la Honorable Cámara de Senadores de la Nación (1927), Buenos Aires, Imprenta y Encuadernación de la Cámara de Diputados, p. 206. 
dra de Enfermedades Infecciosas de la Universidad de Buenos Aires, prefería la creación de espacios para la atención de leprosos en sanatorios generales de las grandes ciudades ${ }^{21}$. Y por otro lado, durante el propio debate parlamentario del Proyecto de Aberastury, representantes de la provincia de Corrientes cuestionaron que se ubicara la colonia donde existían los mayores focos de lepra. El senador nacional por esa provincia, Ricardo Caballero proponía en cambio parajes lejanos a esos focos, «si se busca la curación o el mejoramiento de los enfermos, porque el clima de las regiones con lepra parece que no es propicio a la mejoría de los enfermos» ${ }^{22}$. La perduración de un sustrato neohipocrático parecía avalar la idea de que ciertos ambientes determinaban la presencia del mal. Si la humedad y los pantanos del Litoral eran entendidos como causales directos de la lepra, la colonia fracasaría al situarse en el mismo sitio que producía la enfermedad. El socialista Juan B. Justo, en cambio, acompañaba la postura gubernamental invocando situaciones no exentas de los ancestrales prejuicios que suscitaba la lepra, al señalar que «llevar a los leprosos muy lejos de donde han caído enfermos, va a ser siempre resistido por los habitantes de las zonas limpias de lepra, por toda clase de razones, ¿qué objeto tendría invadirlos oficialmente, sanitariamente con la lepra, cuando ellos no la tienen? Hay que formar colonias donde está la lepra» ${ }^{23}$.

El temor al contagio signó entonces la principal tensión entablada en torno a la decisión de las autoridades de crear una gran colonia de alcance nacional y la respuesta de los representantes de la Provincia de Corrientes que poseía núcleos urbanos relativamente próximos al sitio elegido. Esa Provincia, con antecedentes importantes en el tratamiento de la Lepra, que iban desde la tradicional Casa de Aislamiento que poseía hasta la primera Ley sobre el tema — sancionada en 1901 dentro de su órbita-, había aportado a través de Antonio Pont, la más precisa propuesta de creación de una gran colonia en una isla. Y aún dos décadas más tarde sus argumentos seguían siendo invocados; sin embargo, el hecho de escogerse para ese fin una isla situada frente a las costas de Corrientes suscitó, en sus representantes parlamentarios, interminables replanteos.

La inhóspita Isla del Cerrito fue convertida en Territorio Nacional y la Ley sobre Lepra fue aprobada en los términos enunciados por Aberastury, es de-

21 En el mismo año 1926, a instancias de Baliña, el Estado destinó fondos para construir un pabellón destinado a leprosos en el Hospital Muñiz. Molinari (2005), p. 173.

22 Diario de Sesiones de la Honorable Cámara de Senadores de la Nación (1926), Buenos Aires, Imprenta y Encuadernación de la Cámara de Diputados, p. 618

23 Diario de Sesiones de la Honorable Cámara de Senadores de la Nación (1926), p. 619. 
cir, prescribiendo la ubicación de la leprosería en dicha Isla. Aún después de esta resolución el senador correntino, Juan Ramón Vidal siguió cuestionando la localización decidida por atribuirle al sitio problemas que impedirían concretar los propósitos perseguidos. De la Ley se desprendía que, para el tratamiento de los leprosos, debía crearse una suerte de colonia agrícola-ganadera, en forma de aldea, y como dicha Isla estaba conformada por esteros y lagunas insalubres, sería imposible llevar a cabo ese plan. No habría suficientes tierras aptas y el sistema de casas separadas con huertas terminaría derivando en pabellones compactos del tipo de las tradicionales colonias. Vidal además cuestionó la inversión decidida, deslizando también una reflexión acerca del carácter que debían poseer los edificios públicos:

«Podrán justificarse los edificios monumentales para escuelas públicas, y asimismo se ha criticado el abuso de ellos. Una escuela monumental puede, por su estética, influir sobre el espíritu de los alumnos, pero un hospital monumental para leprosos, no sé sobre quiénes va a producir efecto; un edificio monumental en una ciudad, puede servir para la estética de la ciudad, pero un edificio en una isla pantanosa e inundable, sólo va a servir para derrochar tres millones y medio de pesos» ${ }^{24}$.

Y si bien Justo avalaba el proyecto, también puso reparos en la inversión propuesta y en la tipología edilicia promovida. En efecto tratándose de espacios para la lepra,

«son construcciones que lo mejor que puede desearse es que dentro de diez años se les prendan fuego y desaparezcan; de modo que pueden ser hechas con relativo poco costo. El clima aquel, muy suave, permite también vivir sin muros muy espesos; habría que hacer espacios aireados, con sombra, limpios, bien tenidos, desagües higiénicos, la destrucción que pueda haber en los residuos, etc.; pero nada más que eso: prescindir de todo propósito monumental» ${ }^{25}$.

Las posturas concordantes de Vidal y Justo prolongaban un debate que, desde la organización nacional en torno a 1880, se abocó a determinar el carácter que debía poseer cada expresión de la arquitectura oficial. Y en él, las respuestas para escuelas y hospitales fueron a menudo planteadas en términos antitéticos, especialmente cuando se les llegó a atribuir a las primeras una importante función simbólica y a los segundos un papel utilitario connotado por la provisionalidad aconsejada desde el discurso higiénico. Justo volvía

24 Diario de Sesiones de la Honorable Cámara de Senadores de la Nación (1927), p. 204.

25 Diario de Sesiones de la Honorable Cámara de Senadores de la Nación (1927), p. 209. 
entonces sobre las recomendaciones científicas decimonónicas de crear «hospitales-barraca» para poder renovar sus instalaciones periódicamente, evitando así las concentraciones «pútridas». El modelo había sido utilizado en la Guerra de Secesión norteamericana y luego Rudolf Virchow lo difundió para que fuera aplicado durante la guerra franco-prusiana. En Argentina, el citado establecimiento de Melchor Romero en La Plata también fue concebido como un «hospital-barraca», mientras en esa ciudad se llevaba a cabo un vasto plan de creación de «Escuelas monumentales» ${ }^{26}$.

Por su parte y aun con las escasas certezas científicas que se tenía en relación a las vías de contagio de la lepra, Vidal agregaba otros cuestionamientos físicos al emprendimiento, insistiendo en los riesgos que entrañaría la Isla del Cerrito para quienes, como los habitantes de Paso de la Patria en Corrientes, habrían de beber el agua en que se arrojaran residuos de una colonia de leprosos ${ }^{27}$.

Poco después de este debate, el gobierno nacional instrumentó el primer Censo oficial de enfermos de Lepra en Argentina, conforme a lo establecido por la Ley 11.359. Y, finalmente decidida la realización de la Colonia en la Isla del Cerrito, una nueva Ley, la 11.410, en 1928, introdujo cambios sobre la anterior para facilitar la concreción del establecimiento. Se eliminó la exigencia de situar la colonia a más de cincuenta kilómetros de un centro poblacional, admitiendo su ubicación en "zonas en que la enfermedad se encuentre más extendida y teniendo en cuenta para su ubicación las garantías de preservación para la población indemne».

La Isla del Cerrito, como la Isla Martín García — propuesta anteriormente por Sommer para esa función-, contenía fuertes connotaciones geopolíticas y representacionales. En efecto, con unas 12.000 hectáreas, se sitúa en la confluencia de los ríos Paraguay y Paraná y debe su nombre a la sobreelevación general de unos 15 metros que sirvió a fines militares en distintas circunstancias, fundamentalmente durante la Guerra de la Triple Alianza, cuando fue bastión de las fuerzas argentinas, brasileñas y uruguayas que en 1866 enfrentaron a Paraguay. Finalizada la guerra, Brasil mantuvo la ocupación de la Isla hasta que en 1876 fue reconocida la soberanía argentina sobre ella y se instaló allí (aunque brevemente) la sede de gobierno del Chaco. La Isla del Cerrito también fue vinculada a la lepra por Fariní, cuando en su tesis doctoral recordaba que allí llegó a instalarse una leprosería ${ }^{28}$.

\footnotetext{
26 VAllejo (2007).

27 Diario de Sesiones de la Honorable Cámara de Senadores de la Nación (1927), p. 205.

28 FARINÍ (1899).
} 
La nueva Ley exacerbó los ánimos de los representantes de Corrientes que siguieron protestando. Debido a estos inconvenientes, el acto de colocación de la piedra fundamental de la Colonia sólo pudo realizarse el 27 de septiembre de 1928 , pero en una curiosa ceremonia, casi secreta, protagonizada por Domingo Cabred. El presidente de la Nación, Marcelo T. de Alvear, le había ordenado a Cabred, una vez embarcado rumbo a la Isla del Cerrito, que suspendiera dicho acto. El médico se negó cumplir esa orden y finalmente el presidente aceptó que se celebrase la inauguración, aunque «pasada la medianoche, en el mayor sigilo $»^{29}$. En ese contexto las obras tuvieron un tortuoso desarrollo, y no fueron concluidas hasta 1938. Pero aun así el senador correntino Juan Ramón Vidal solicitó un nuevo informe con el fin de impugnar su habilitación ${ }^{30}$. Otra vez insistió sobre el costo de las instalaciones, articulándose este argumento con la vieja forma de combatir el contagio a través de construcciones provisorias «modestas y económicas para destruirlas por el fuego» ${ }^{31}$.

La Colonia del Cerrito pudo abrir sus puertas el 30 de marzo de 1939, y adoptó el nombre de Maximiliano Aberastury. Su inauguración fue acompañada por el surgimiento de otras cuatro colonias más: la «Pedro Baliña» de Misiones, la «José Puente» de San Francisco del Chañar, Córdoba, la «Baldomero Sommer» de General Rodríguez, Provincia de Buenos Aires y la «Enrique Fidanza» de Diamante, Provincia de Entre Ríos.

La Colonia mantuvo en su organización general el modelo previsto, aunque con ciertas inflexiones. El establecimiento se compuso de 22 pabellones, cuya rigidez fue moderada un tanto por los clichés de la arquitectura inglesa suburbana. Igualmente, la idea originaria de dar lugar a casas separadas para que los leprosos colonizaran la isla virginal, no fue completamente abandonada. Inicialmente esa idea quedaba restringida a aquellos enfermos que por ser ricos podían efectivamente afirmar su estatus a través de una identificación física de distanciamiento respecto de los espacios comunitarios que concentraban a enfermos pobres. La propia Ley 11.359 que - con la ínfima modificación introducida por la Ley 11.410 en 1928 - reguló la profilaxis de la lepra en Argentina hasta $1983^{32}$, ya había previsto esa situación, prescribiendo un tratamiento diferencial del leproso según fuese pobre o rico. Se propendía a que los enfermos con recursos suficientes que decidieran instalarse en las

29 Quiroga (1964), pp. 102-103.

30 MOLINARI (2005), p. 179.

31 Cfr. MOLINARI (2005), p. 179.

32 La Ley 22.964, dictada en noviembre de 1983, deroga a las leyes 11.359 y 11.410 . 
colonias —el pobre no tenía esa opción —33, pudieran construir sus propias viviendas «en parajes inmediatos al núcleo principal de la población sanitaria», para habitarlas «solos o en pequeños grupos familiares». Ellos podían dedicarse a los mismos trabajos que los demás enfermos de la colonia, conjunta o separadamente, y gozaban de una «vida libre» dentro de las restricciones de orden general. Sin embargo, en la puesta en marcha de la Colonia era manifiesta la homogeneidad de origen de los asilados, leprosos pobres, aunque efectivamente la vida en el establecimiento generaba luego las diferencias que se afirmaban con la posibilidad de que cada uno levantara su propia vivienda, que no sería un chalet sino un rancho. Como el Estado contrataba para tareas administrativas a los propios enfermos - retomando con ello una vieja idea de Pont y Sommer-, enviaba fondos que, por insuficientes, sólo permitían el desempeño de una parte de la población, la más capacitada para las tareas, y la que sufría menores efectos de la enfermedad. El resto quedaba desempleado, agregando un estigma más al drama con el que habían llegado.

Veinticinco años después de la inauguración de la Colonia del Cerrito existían cuarenta grandes edificios, noventa y cinco empleados y el total de enfermos ascendía a doscientos cuarenta y uno. Los pabellones inicialmente edificados quedaban dentro de una zona de reclusión de diez hectáreas, más allá de la cual se distribuían los edificios de la administración y vivienda del personal sano. Todo allí estaba «limpio, cuidado, paradisíacamente ordenado» ${ }^{34}$. Durante ese lapso, y merced a reglamentos internos que fueron flexibilizando el criterio de la ley, el tratamiento había logrado mejoras sustanciales en las condiciones de los pacientes. Y cuando paralelamente, la «laborterapia» iba exhibiendo notables resultados se produjo el cierre: aquella atemorizadora isla pantanosa que integraba un Territorio Nacional bajo jurisdicción del área de salud, al transformarse en un extendido parque natural por obra de los hansenianos, fue objeto de gestiones de la provincia de Chaco para incorporarla a su jurisdicción $\mathrm{y}$, una vez concretado esto, convertirla en un centro turístico.

\section{LEPRA Y EUGENESIA: PROTEGER LA RAZA}

El aislamiento físico de los leprosos fue entendido como una solución sólo parcial dentro de la estrategia de «defensa social» en la que el tratamiento

33 En efecto, existía la presunción de la ineficacia del aislamiento domiciliario del pobre.

34 WaLSH, R. (1998) [1965], La isla de los resucitados. En El violento oficio de escribir. Obra periodística (1953-1977), Buenos Aires, Planeta. 
sanitario quedó inmerso. La restricción de derechos complementó los alcances y puso particularmente de manifiesto cómo el problema era abordado desde la eugenesia.

La eugenesia, como disciplina con vocación de organizar poblaciones a partir del imperativo de controlar su reproducción - física, pero también ideológica-, focalizó particularmente su atención en la transmisión hereditaria de una u otra característica física o mental concebida como no valiosa y, en consecuencia, tipificada patológica. En esta sintonía, y dada la significativa recepción del paradigma eugénico en Argentina -ya sea asociado al determinismo genético o al ambiental-35, las indagaciones sobre la herencia normal y la herencia mórbida constituyeron, durante las primeras décadas del siglo XX, una preocupación constante de las élites intelectuales y políticas.

Ahora bien, con respecto a la lepra queda expuesta en este período una clara tensión entre el conocimiento médico de que se disponía sobre esa enfermedad y las previsiones eugenésicas que también formaban parte del capital científico de las mismas elites. Dicha tensión se resolvió en el plano político a través de la instrumentación de diversos dispositivos de aislamiento de los leprosos, más asociados a estrategias de segregación social — cuya búsqueda de legitimación científica las conducía al paradigma eugenésico-, que a indicaciones terapéuticas.

En efecto, ya en la Conferencia sobre la Lepra de 1906, quedaron planteadas sobre este tema dos premisas directrices: por una parte, que la lepra era contagiosa, y, por otra, que la lepra dudosamente era transmisible por herencia. Transmisión por contagio y herencia constituían, pues, los dos platillos de una balanza cuya inclinación hacia el primero requería evaluar cuidadosamente

35 Una serie de trabajos recientes iluminan el impacto de la tesis de Galton en Argentina. Entre ellos: SCARZANELlA, E. (1999), Italiani malagente. Inmigrazione, criminalità, razzismo in Argentina, 1890-1940, Milano, Franco Angeli; MIRANDA, M. (2003), La antorcha de Cupido: eugenesia, biotipología y eugamia en Argentina, 1930-1970, Asclepio, 55 (2), 231-255; VALLEJO, G. (2004), El ojo del poder en el espacio del saber: los Institutos de Biotipología, Asclepio, 56 (1), 219-244; VALlejo, G. y MirandA, M. (2004), Los saberes del poder: eugenesia y biotipología en la Argentina del siglo XX, Revista de Indias, 64 (231), 425-444; MIRANDA, M. (2005), La biotipología en el pronatalismo argentino (1930-1983), Asclepio, 57 (1), 189-218; Palma, H. (2005), Gobernar es seleccionar. Historia y reflexiones sobre el mejoramiento genético en seres humanos, Buenos Aires, Baudino. Y situando la realidad argentina dentro de un contexto mas amplio: STEPAN, N. (1991), The hours of Eugenics, Ithaca and London, Cornell University Press; Miranda, M. y VAllejo, G. (comp.) (2005), Darwinismo social y eugenesia en el mundo latino, Buenos Aires, Siglo XXI; GARCÍA GoNZÁlez, A. y Álvarez PelÁEZ, R. (2007), Las trampas del poder, Madrid, CSIC. 
potenciales desviaciones a una estrategia biopolítica mayoritariamente aceptada. En este sentido, cabe destacar que por entonces tenía fuerte consenso la tesis de que la lepra familiar no era fruto de la herencia, sino del contagio ${ }^{36}, \mathrm{y}$ no alcanzaba, por ende, a «los hermanos que se aíslan a tiempo» ${ }^{37}$, ni a los hijos de leprosos separados de los padres al nacer, puesto que, «huérfanos hijos de padres sanos, criados por leprosos, adquieren lepra» ${ }^{38}$; de donde se afirmaba enfáticamente que «muchos de los casos aparentemente hereditarios por tener padres leprosos, no son más que casos de contagio» ${ }^{39}$.

Adquiriendo sustento la hipótesis del contagio, cobraba sentido el aislamiento físico del enfermo, no como medida terapéutica para sí mismo sino como estrategia profiláctica para el resto de la sociedad. De ahí que parecía «mucho más humano proteger a los hombres contra la lepra, que proporcionar al leproso el derecho y la ocasión de hacer otros leprosos $\rangle^{40}$. Pero la propuesta de aislamiento del leproso, seguramente influida en estos congresistas por «la repugnancia y el asco que inspira ${ }^{41}$, resultaba una ardua tarea, ya que, se aseguraba, «el egoísmo prima en el leproso, y la familia no cree en el contagio» ${ }^{42}$. Ante esta reticente actitud del enfermo era menester rescatar aquella vieja tesis de Benjamín Solari sobre la «perversión moral del leproso»» ${ }^{43}$ y el Estado, como gestor de una pretensa «defensa social», debía aislar compulsivamente al enfermo, separándolo de sus bienes y afectos ${ }^{44}$.

\section{0-211.}

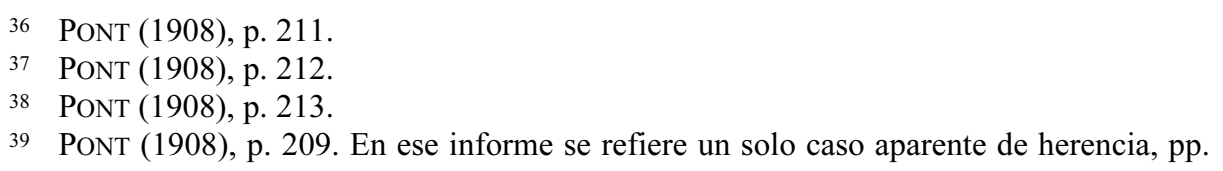

39 PONT (1908), p. 209. En ese informe se refiere un solo caso aparente de herencia, pp.

40 «El tratamiento racional entonces, es, separar por doloroso que sea, al leproso sano [sic] hospitalizarlo, poniéndole en condiciones de asistencia, beneficiándolo y librando a los demás del germen que puede enfermarlos». PONT (1908), p. 224.

41 PONT (1908), p. 226.

42 PONT (1908), p. 228.

43 Según esta tesis, los enfermos de lepra presentan aberraciones e instintos morbosos a propagar el contagio a sus semejantes, razón por la cual resultaba imperioso internarlo y aislarlo. Véase Solari, B. (1898), Perversiones morales en los leprosos, La Semana Médica, (5), p. 351 .

44 «He presenciado escenas angustiosas entre madres e hijos enfermos, que por persuasión nunca se separarán, prefiriendo el sacrificio a la separación, y tengo la convicción íntima de que por persuasión, tratando de demostrar y convencer a enfermos y parientes, de la conveniencia del aislamiento, nunca - a no cambiar grandemente la cultura general del puebloconseguiremos la reclusión voluntaria (...)». Sugería «apelar a los medios coercitivos y sancionar una ley de aislamiento obligatorio». PONT (1908), p. 229. 
No obstante, esta condena al ostracismo admitía excepciones ajenas a la transmisión del mal, como lo ponía de manifiesto el representante de Corrientes con la mencionada propuesta de tratamiento desigual de leprosos, según fuesen ricos o pobres. Paralelamente, el delegado del gobierno de Entre Ríos propuso el aislamiento facultativo, ya que no creía muy natural poder «impunemente coartar las libertades personales» ${ }^{45}$; mientras que el delegado de Córdoba intentó imponer el aislamiento absoluto de los leprosos en sus domicilios o en leproserías especiales, a elección del paciente ${ }^{46}$. Sommer, delegado de la Capital Federal, auguraba la imposibilidad de lograr el aislamiento obligatorio de todos los enfermos, y creía más eficaz el facultativo, a la vez que recomendaba «incitar a los dueños de fábricas o talleres a que no den trabajo a los leprosos»; recayendo otro tipo de obligaciones sobre los enfermos que no se aislaran ${ }^{47}$.

La idea de aislamiento del enfermo como defensa social y no como medida terapéutica, fue nuevamente reiterada en el Proyecto de Ley elaborado por Tomás de Veyga en 1914 a instancias de Solari. En los fundamentos de este proyecto se insistía en la particular «premeditación» y «astucia» con que los leprosos pretenderían contagiar su mal, hechos ante los cuales no se debía permanecer impasible:

«la uniformidad de la alteración moral en los diversos actos cometidos con perfecta conformidad e integridad intelectual, convence de que esos sujetos son peligrosos, sumamente peligrosos, y que sus atentados contra el orden social deben ser definidos como delitos, con toda claridad y rigor, para salvar a los más de estos ataques de $\operatorname{los}$ menos» ${ }^{48}$.

Por su parte, además de preverse por la Ley 11.359 el aislamiento obligatorio a domicilio, bajo vigilancia directa del Estado y el aislamiento en establecimientos oficiales cuando los pacientes no tuviesen recursos suficientes, existía, a su vez, un tratamiento preferencial a los enfermos según tuviesen o no posibilidades de «restitución integral a la vida común». Los cónyuges le-

45 ChiarA, J. (1908), Informe presentado por el Dr. Juan L. Chiara, delegado por la Provincia de Entre Ríos, Conferencia sobre la Lepra (1908), pp. 253-259, p. 259.

46 RocA, E. (1908), Informe presentado por el Dr. Eduardo Roca, delegado por la Provincia de Córdoba. Conferencia sobre la Lepra (1908), pp. 267-299, p. 275.

47 Informe presentado por el Dr. Baldomero Sommer, delegado por la Capital Federal. Conferencia sobre la Lepra (1908), pp. 307-313, pp. 308-309.

48 De Veyga, T. (1914), Tratamiento sanitario de los leprosos, La Semana Médica, 21 (44), 724-734, p. 732. 
prosos y sus hijos leprosos eran alojados en forma que pudieran continuar en los sanatorios o colonias su vida familiar. Pero esa continuidad se veía trastocada si existía un hijo «no leproso», puesto que para la Ley éste debía «ser aislado de sus padres leprosos cuando la enfermedad de éstos comporta amenaza de contagio», aislamiento que se cumplía «con la separación de la madre leprosa o del padre leproso o de ambos». Si esos hijos eran recién nacidos, se los destinaba a «cunas o asilos comunes, bajo observación insistente y prolongada», siempre y cuando el examen médico minucioso comprobara que estaban absolutamente libres de toda manifestación de enfermedad y no eran portadores de bacilos leprosos». Del mismo modo, se autorizaba a concurrir a «escuelas o talleres comunes» a «los niños hijos de leprosos que no tuvieran síntomas de enfermedad y que no fueran portadores de gérmenes leprosos»» estaban obligados, empero, a someterse a frecuentes inspecciones médicas.

Este aspecto de la Ley fue el que se aplicó más estrictamente, aun cuando se tuviera la certeza de que la lepra no era hereditaria, y el director de la Colonia del Cerrito en los años sesenta, el Dr. Iglesia, insistiera en señalar que era «la enfermedad menos contagiosa de todas las infectocontagiosas $>49$. Para las separaciones forzosas de los bebés nacidos ilegalmente - esto es fuera del matrimonioen colonias como la del Cerrito, estaba previsto un destino: el establecimiento «Mi Esperanza» en La Matanza, Provincia de Buenos Aires, creado especialmente y en estricto cumplimiento de la Ley, para recibir los hijos de leprosos ${ }^{50}$.

Cabe preguntarse entonces ¿en qué lógica científica se sustentó la prohibición del matrimonio «entre leprosos» o entre «una persona sana con una leprosa» establecida también por la Ley 11.359, que no impedía, empero, la convivencia $-\mathrm{y}$ consiguiente cohabitación - de un matrimonio en el cual uno o ambos cónyuges hubiesen contraído la enfermedad luego de una unión legalmente válida? ${ }^{51}$.

49 La aplicación de la Ley hizo bajar radicalmente el índice de nacimientos entre los leprosos, debido al creciente pedido de las mujeres de ser esterilizadas mediante la ligadura de trompas. Testimonios de la Colonia del Cerrito reflejaban claramente esa situación: «Y sí dice Ramona Falcón, de 19 años, yo le pedí. Y para qué. Una queda a sufrir acá, y las criaturas se van». WALSH (1998).

50 Ramona recordaba que a sus tres hijos apenas los había alcanzado a ver cuando los tuvo «y después se los llevaron. Ni tenerlos un rato, ni tocarlos, ni nada. Y sí, después le mandan la foto, y le dicen cómo estaban y que aumentaron de peso. Pero no es lo mismo. Una siempre los extraña». WALSH (1998).

51 Más adelante veremos que desde la Sociedad Argentina de Eugenesia se propició, años después, la separación compulsiva de los cónyuges cuando uno de ellos adquiriera una enfermedad disgénica. 
El temor al contagio seguía siendo clave en esto. Por eso el Patronato de Leprosos se puso al frente de una Colonia para niños sanos,

«hijos o convivientes de enfermos de lepra, quienes se encuentran expuestos al peligro de contagio, al convivir con sus padres. Este Asilo permitirá que esas criaturas, que hasta ahora no pueden ser admitidas en ninguna Asociación por el temor de que aparezca en ellas algún signo de infección específica, reciban los cuidados y educación necesarias para que puedan ser útiles a sí mismos y a la sociedad, librándolos del destino cruel a que estaban expuestos» ${ }^{52}$.

Sea como fuere, es decir, existiera o no una legitimación proporcionada por el estado de la ciencia de la época, lo cierto es que la restricción de derechos promovida motivaba inquietud. En el debate parlamentario de 1926, el senador por la provincia de Santa Fe, Ricardo Caballero, vio con preocupación las diversas restricciones a las libertades individuales en ella previstas, más aún, en un país como la Argentina, donde — según él - no existían focos de lepra ${ }^{53}$. Además, estando por entonces bastante consolidado el argumento de la no transmisión hereditaria de la lepra, aquel senador afirmaba que

«ni siquiera los hijos de leprosos heredan una susceptibilidad especial para adquirirla. [...] Por este proyecto, llegará un momento en que hasta a los sospechosos de padecer de lepra se les arrancarán sus hijos, se les destruirá su familia, todo en nombre de alguna denuncia más o menos indocta» ${ }^{54}$.

Pero los cuestionamientos apuntaban también a describir una situación por demás preocupante, como lo era la vinculada al diagnóstico efectivo de la enfermedad con las implicancias jurídicas que conllevaba. Así, ¿quién haría las denuncias de que tal o cual persona padece lepra en los casos infinitos en que ésta se presenta con caracteres no claros? Siendo, como era, una enfermedad de difícil detección, y estando involucrado de tal forma el cercenamiento de las libertades individuales en pos de un pretendido bien social, para Caballero - quien no dudaba en afirmar: «Toda esta legislación es monstruo-

52 Casares de Blaquier, H. y Bunge de Uranga, J. (1939), Asistencia social al enfermo de lepra, Anales de Biotipología, Eugenesia y Medicina Social, (83), 21-23, p. 23.

53 En efecto, este legislador entendía que debía ponerse un límite a «esta clase de legislación respecto de la libertad individual que compromete, extraviada por las sugestiones de una ciencia que no posee ninguna verdad absoluta sobre esta materia y que carece de piedad para la desgracia». Diario de Sesiones de la Honorable Cámara de Senadores de la Nación (1926), p. 602 .

54 Diario de Sesiones de la Honorable Cámara de Senadores de la Nación (1926), p. 605. 
sa»——55, requería como condición indispensable la demostración de la presencia del bacilo en la lesión ${ }^{56}$.

Pero claro está, el llamado de atención que se hace respecto al cuidado que requiere legislar con un "criterio científico aparente», comprometiendo, por ello, libertades fundamentales, fue contestado por el senador Gallo, para quien sólo era digno de la libertad individual el que era capaz de ganársela diariamente por sí mismo ${ }^{57}$.

Más allá de estos puntos de tensión, la Ley tuvo una larga vigencia, y las discusiones posteriores se centraron no en el aislamiento en sí, ya fuera físico (en leproserías, asilos, colonias o en pabellones anexos a hospitales públicos) o simbólico (interdictando al enfermo), sino en la forma de hacer efectivo dicho aislamiento físico, y su lugar concreto de instalación. Aun así, poco antes de la conflictiva inauguración de la Colonia en la Isla del Cerrito, Nicolás Greco reflexionaba sobre la separación forzosa de los hijos sanos de sus padres leprosos y la exclusión de los leprosos de las profesiones en las que podían transmitir su enfermedad ${ }^{58}$, retomando las conclusiones de la Tercera Conferencia Internacional de la Lepra, reunida en Estrasburgo en 1923, donde se recomendaba que el aislamiento fuera humanitario y dejara al leproso en las proximidades de su familia. Recuperando el debate sobre la herencia, afirmaba que la «lepra hereditaria» era una «forma de transmisión poco frecuente y lo comprobarían los recién nacidos que separados de la madre enferma, es raro que tengan lepra más tarde ${ }^{59}$. No obstante, seguía sin plantearse una eventual revisión de la prohibición matrimonial.

Entonces, si ya hacia la década de 1930 estaba consolidada la tesis de la no heredabilidad de la lepra y, el aislamiento de los hijos sanos de padres enfermos se fundaba en la posibilidad de contagio, ¿por qué se mantuvo incuestionable la prohibición de contraer matrimonio? ${ }^{60}$.

Y aquí cobra sentido la vertiente eugénica-ambiental que primó en Argentina fundamentalmente desde el período de entreguerras. En efecto, para sus impulsores, el medio, infectado, poluto, corrupto, inmoral, era el princi-

\footnotetext{
55 Diario de Sesiones de la Honorable Cámara de Senadores de la Nación (1926), p. 617.

56 Diario de Sesiones de la Honorable Cámara de Senadores de la Nación (1926), p. 614.

57 Diario de Sesiones de la Honorable Cámara de Senadores de la Nación (1926), p. 638.

58 Greco, N. (1937), La profilaxis de la lepra, La Semana Médica, 44 (44), 1023-1033, p. 1024.

59 GRECO (1937), p. 1028.

60 Para profundizar sobre el sustrato eugénico de este impedimento, véase: DíAZ DE GUIJARRO, E. (1944), El impedimento matrimonial de enfermedad (matrimonio y eugenesia), Buenos Aires, Guillermo Kraft.
} 
pal factor disgénico y, para controlarlo, no sólo era menester ampliar el listado de impedimentos matrimoniales vinculados a las enfermedades hereditarias, sino además, incluir las contagiosas ${ }^{61}$, sin detenerse demasiado en su eventual transmisión a la descendencia ${ }^{62}$. Así, desde esa corriente «ambientalista» — también llamada «eugenesia integral positiva» por el abogado Carlos Bernaldo de Quirós - se consideró que la Ley de Profilaxis de la Lepra formaba parte del plexo normativo eugenésico dictado en el país ${ }^{63}$; mientras que se sostuvo que la herencia no debía ser mirada «sólo con vistas al régimen sucesorio, a la transmisión gratuita de bienes civiles y a la familia, sino como factor etiológico de ciertas anomalías fisiológicas funcionales y de incapacidades biojurídicas, que son su lógico desencadenamiento patológico» ${ }^{64}$.

De este enfoque se derivó, por una parte, la obligación de fichar «la vida y la salud de los habitantes, tal cual hoy se registra la vida y haciendas del pueblo», propiciado por otro eugenista, Germinal Rodríguez, quien ya en 1927 propuso crear un Registro de Sanidad homologable al Registro de la Propie$\operatorname{dad}^{65}$. Y, por otra, la constatación estatal de la «aptitud nupcial mediata» antes de autorizar la celebración de un matrimonio, sostenida por Díaz de Guijarro. Desde esta perspectiva, a diferencia de la exigibilidad de la aptitud nupcial inmediata - concentrada en circunstancias coyunturales - se debía, además, requerir la capacidad de engendrar y la posibilidad de lograr una descendencia sana. Díaz de Guijarro planteó esto en la Primera Jornada Peruana de Eugenesia (Lima, 1939) junto a la conveniencia de instaurar la obligatoriedad del certificado médico prenupcial como diligencia previa al matrimonio, exigible a ambos contrayentes; y la viabilidad del divorcio cuando se revelara o se adquiriera una enfermedad crónica, contagiosa y/o hereditaria, principios éstos que fueron reiterados en la Segunda Jornada Peruana de

61 Esta postura fue insistentemente sostenida desde la Sociedad Argentina de Eugenesia, institución altamente representativa del eugenismo argentino de la segunda posguerra y de la cual Díaz de Guijarro era su vicepresidente.

62 Cabe destacar, empero, la mesura con la que Frías se manifestó en el Segundo Congreso de Derecho Civil respecto de la incorporación en el Código de los impedimentos eugénicos de lepra y venéreas, en virtud de sus dudas sobre las conclusiones de la eugénica, que «están sujetas a revisión». FRÍAS, J. (1941), El matrimonio, sus impedimentos y nulidades, Córdoba, El Ateneo, p. 179.

63 Bernaldo De Quirós, C. (1943), Eugenesia Jurídica y Social (Derecho Eugenésico Argentino), Tomo I, Buenos Aires, Ideas, p. 63.

64 BERNALDO DE QuiRós (1943), p. 75.

65 Rodríguez, G. (1927), Registro de sanidad de la República, La Semana Médica, 34 (48), 1537-1538, p. 1538. 
Eugenesia (Lima, 1943) y en el Segundo Congreso Nacional de Facultades de Derecho (Potosí, 1940)66. Así, la prohibición para contraer nupcias que recaía sobre enfermos venéreos, leprosos, tuberculosos, epilépticos, alienados, oligofrénicos y sordomudos era un obstáculo que desaparecería al haber pasado el período de contagio, pero, eso sí, siempre y cuando no hubiera riesgo para la descendencia ${ }^{67}$.

A su vez, las preocupaciones vinculadas a la lepra y sus potencialidades de actuar como factor disgénico, no quedaban reservadas al ámbito jurídico y de los impedimentos matrimoniales. La principal institución orientada a difundir en el campo intelectual los contenidos de la ciencia de Galton, la Asociación Argentina de Biotipología, Eugenesia y Medicina Social, invitó en 1943 al Dr. Aller Atucha para que comentara los nuevos aportes al tratamiento de la lepra. ${ }^{68}$ Unos años antes, el Patronato de Leprosos también había tenido activa participación en las Jornadas sobre «La Asistencia Social» organizadas por la Asociación de Biotipología, publicitando la labor de incentivo que realizaba, premiando a los pacientes que se atendían en el Hospital Muñiz: «Este sistema, de gran resultado práctico y estadístico, consiste en entregar al enfermo, cada vez que concurre al Dispensario de acuerdo con la indicación médica, un bono canjeable por dinero en efectivo» ${ }^{69}$.

La herencia, aquí tampoco, surgía como problema. El contagio, sí, pero los intercambios entre la más representativa institución eugénica argentina de la década de 1930-1940 y las organizaciones vinculadas a la asistencia y protección del leproso formaban parte de un continuum que incluía a Eduardo Bunge y su participación como representante del Patronato de Leprosos en el Primer Congreso Argentino de Sociología y Medicina del Trabajo, organizado por la Asociación Argentina de Biotipología, Eugenesia y Medicina Social; así como la intervención del director de ésta última entidad, Arturo Rossi, en la Primera Conferencia de Asistencia Social de la Lepra celebrada en Buenos Aires en 1939. En aquella oportunidad, Bunge destacó el «profundo sentimiento de justicia» de monseñor de Andrea, demostrado en la afirmación: «un derecho puede renunciarse, pero el deber no se puede renunciar», para trasladar este concepto del individuo a la colectividad humana, que re-

66 DíAZ de Guijarro (1944), pp. 19-21.

67 En general, los eugenistas argentinos coincidían en atribuir a este tipo de enfermedades características contagiosas y hereditarias.

68 Véase: Aller Atucha, J. (1943), Nuevos aportes al tratamiento de la lepra, Anales de Biotipología, Eugenesia y Medicina Social, (100), 17-31.

69 Casares de Blaquier, Bunge de Uranga (1939), p. 21. 
cluye al enfermo de lepra, privándolo de su libertad más en beneficio de ella que del enfermo mismo» ${ }^{70}$.

Por entonces, el aislamiento del leproso previsto en la Ley Aberastury parecía haber dado los resultados esperados: «al ser recluidos o aislados debidamente los enfermos de lepra, las posibilidades de contagio quedan reducidas en forma tal que casi podrían considerarse nulas» ${ }^{71}$.

No obstante, fue en la referida Primera Conferencia de Asistencia Social de la Lepra donde quedó bien expuesta la imbricada relación entre el abordaje biopolítico otorgado en Argentina a una enfermedad eminentemente contagiosa, cuya transmisión a la descendencia ya estaba por entonces descartada: la lepra; y una disciplina dedicada al control de la herencia: la eugenesia. En ese ámbito, el médico eugenista Arturo Rossi, aunque aceptaba la contagiosidad de la lepra, rescató la importancia del factor hereditario y constitucional en la adquisición de esa enfermedad, puesto que no se enfermaban «médicos, practicantes, hermanas de caridad ni enfermeras» que asistían a los hansenianos. Así, retomó el anacrónico concepto de «lepra familiar», afirmando que existían "verdaderas familias de leprosos», y que al separar a un hijo recién nacido de madre leprosa, aquél desarrollaría su lepra más tarde, en lugar alejado de sus familiares enfermos. Acude entonces Rossi a los «cultores de la patología constitucional» ${ }^{72}$ para sostener su tesis de la «posible existencia de un terreno constitucional en la lepra», en forma muy semejante a como se evaluaba, por entonces, el terreno constitucional en la tuberculosis: es decir, «la existencia de un estado de labilidad de aquellos biotipos humanos, en los cuales se desarrolla la enfermedad originada por el bacilo de Hansen ${ }^{73}$. De ahí que este eugenista sugiriera enfocar el problema de la profilaxis antileprosa dentro de los cánones de la medicina preventiva, para «dilucidar en los familiares o personas que convivan con los leprosos la existencia de predisposiciones automorbosas y paramorbosas $\rangle^{74}$.

Pero según el director de la Asociación Argentina de Biotipología, Eugenesia y Medicina Social, el tema central convocante en esa Conferencia era

70 Bunge, E. (1940), Función del Estado y la Asistencia Social en la lucha antileprosa, Anales de Biotipología, Eugenesia y Medicina Social, (91), 15-16, p. 15.

71 BUNGE (1940), p. 16.

72 Esta disciplina, de fuerte impacto en la Italia fascista, tuvo como principales representantes en ese país a Giacinto Viola y Nicola Pende.

73 Rossi, A. (1939), Primera Conferencia de Asistencia Social de la Lepra. La prevención médico social en la lepra, Anales de Biotipología, Eugenesia y Medicina Social, (88), 14, p. 3.

74 Rossi (1939), p. 3. 
«la protección al hijo sano, del enfermo de lepra», y concluía: «la prevención médica y social de la lepra debe también ser contemplada estudiando las características físicas y psíquicas del hijo sano de padres leprosos, para dilucidar de tal suerte si es que existen en realidad taras hereditarias que puedan ser modificables con un tratamiento adecuado o aquellas otras ectopias morfológicas dinámico-humorales o neuroendocrinas, que puedan favorecer a título de constitución más apta el desarrollo del mal». En definitiva, destacaba la necesidad de «practicar una higiene mental en estos niños sanos de padres leprosos; que han tenido la desgracia de llegar al mundo más que con una tara orgánica, con una terrible tara social». Para Rossi, esos hijos albergaban «un estado de equilibrio inestable de su propia personalidad psicológica; su complejo de inferioridad ha[bía] abierto una profunda herida en el fondo de su alma» y esa herida obraba en desmedro de su «propio sentimiento de comunidad», todo lo cual se veía favorecido por el estigma ancestral que llevaban y que había generado en ellos un estado de neurosis latente por desequilibrio de la esfera subconsciente. De ahí se imponía

«a la par que el conocimiento y por ende el tratamiento adecuado de las taras hereditarias, el tratamiento de los desequilibrios morfológicos y glandulares y el tratamiento psíquico de ese otro no menos grave desequilibrio del espíritu; todo lo cual sintetizamos bajo el rubro de medicina preventiva aplicada a la profilaxis antileprosa» ${ }^{75}$.

Así, la articulación entre eugenesia y profilaxis de la lepra quedaba planteada mediante la prevención - y nueva estigmatización- de los descendientes sanos de leprosos, a través de la higiene mental y la psicoterapia.

\section{AiSLAMIENTO Y CONTROL SOCIAL}

El discurso médico y el legal, a menudo ensamblados en Argentina por la influyente presencia de la eugenesia, llegaron a concebir la exclusión de agentes nocivos al sistema de derecho como mecanismo de defensa de la raza. Enfermedades, rasgos fenotípicos, ideas políticas o credos religiosos, formaron parte de un universo de la «otredad» del que debía quedar protegida la ciudadanía «normal». La lepra fue, dentro de ese contexto, un motivo explícito de invocación para legitimar formas de aislamiento físico y simbólico que,

75 Rossi (1939), p. 3. 
si bien operaban sobre un universo reducido —el de los leprosos-, también tenían una función ejemplarizadora sobre la sociedad «normal», señalándole los «desvíos» de los que debía protegerse.

La lepra se constituyó así en un estigma cuyas tradicionales connotaciones reaparecían dentro de la eugenesia latina - como también afloraban en este constructo ideológico respuestas tradicionales fundadas en el trasfondo «ambiental» del hipocratismo y la teoría humoral- ${ }^{76}$.

El tratamiento biopolítico que preponderantemente recibió la lepra, ilumina el problema mayor del ejercicio de un amplio control social sobre la población desde el particular protagonismo asumido por la eugenesia y reflejado en el abordaje de las enfermedades «peligrosas». Desde ese protagonismo, se prolongaron los rasgos de una higiene defensiva preocupada por la normalización de la sociedad, que protegiera a los sanos y a la vez pusiera a prueba que ellos efectivamente lo eran. En ese contexto los rasgos inclusivos de esta estrategia pudieron fluir en prácticas que evidenciaron avances terapéuticos, pero sólo como parte de políticas esencialmente excluyentes. Así la defensa social - expresada con crudeza en la instrumentación tanto del aislamiento físico como del simbólico - asociada a medidas preventivas sobre la descendencia y a la escasa preocupación por la profilaxis del enfermo en sí, nos remiten a aquella «contagiofobia» descripta por Barrán y entendida como una forma de miedo burgués a los otros en ropaje de pobres, «pues en ellos residía tanto la enfermedad como la posibilidad de la violencia social $\gg^{77}$.

Fecha de recepción: 14 de septiembre de 2007.

Fecha de aceptación: 3 de abril de 2008.

76 Sobre la eugenesia latina y su teoría que refleja la perduración del corpus hipocrático, véase VAllejo, G. (2007), La imagen del hombre en la eugenesia latina. En VALLEJO, G. y Miranda, M. (eds.), Políticas del cuerpo. Estrategias modernas de normalización del individuo y la sociedad, Buenos Aires, Siglo XXI.

77 BARrán, J. (1995), Medicina y sociedad en el Uruguay del Novecientos, Tomo 3, Montevideo, Ediciones de la Banda Oriental, p. 270. 